\title{
Analysis, Modelling and Measurement of the Effects of Aluminium and Polymer Heatsinks on Conducted EMC in DC-DC Converters
}

\author{
I. Grobler ${ }^{1}$, M. N. Gitau ${ }^{2}$ \\ Department of Electrical, Electronics and Computer Engineering, \\ University of Pretoria, Pretoria 0001, South Africa \\ igrobler@csir.co.za ${ }^{1}$, njoroge.gitau@up.ac.za ${ }^{2}$
}

Abstract-Effects of polymer heatsink materials on EMI noise in converters have not been adequately investigated. Heatsinks provide a path to ground for the common-mode noise. Selecting an appropriate heatsink material can therefore help reduce common-mode noise by increasing noise path impedance. Effects of heatsinks on EMI noise over the conducted frequency band will be investigated. The critical parameter is the heatsink-to-device capacitance and accurate models of the heatsink impedance need to be developed. This is necessary for results that are accurate enough to allow prequalification of a converter as would happen in an accredited environment. However, simplified common-mode and differential-mode models of the step-down DC-DC converter circuit are adequate to predict the effects of the heatsink on the conducted noise. This paper will demonstrate that compared to a solid aluminium material, using polymer material incorporating conductive fillers in low power converters can greatly lower the device-to-heatsink capacitance, and still be adequate for heat dissipation in lower powered converters. This in turn reduces common-mode noise in the frequency band below $30 \mathrm{MHz}$. The measurement test setup is configured according to the MIL-STD-461F accredited test environment. It consists of a wideband two-port LISN, a properly grounded copper sheet as required by the standard, a suspended feed-line from the LISN to the DUT and an oscilloscope recording the data.

Keywords - conducted EMC, common-mode, differential-mode, polymer heatsinks, lumped-element, wideband digital measurement, digital noise separation. 


\section{INTRODUCTION}

Managing electromagnetic interference (EMI) in a switch-mode power converter should be made an integral part of the design process, thus optimising the overall system design. This improves the design efficiency and shortens the crucial time to market period [1], [2]. It is also beneficial to be able to model the electromagnetic compatibility (EMC) issues concurrently with the power components as well as thermal management design phase [3]. The parasitic couplings between the semiconductor power devices and the heatsink are largely responsible for common-mode currents [4]. Due to the normally large physical size of the heatsink, it has a huge effect on the transmission of unwanted noise [5].

A heat conducting plastic is a polymer composite material in which for increased heat conductivity, a high-heat conductivity filler is added [6]. The thermal conductivity of thermoplastics that are intrinsically not thermally conductive can be improved remarkably by adding highly conductive inorganic fillers such as graphite, carbon black, carbon fibres, ceramic, or metal particles [7], [8]. Desirable properties that would not be achievable through the use of a single material can be obtained. Thermally conductive compounds are generally not considered to be direct drop-in replacements for metals. However, they do offer a broad range of new opportunities for thermal management applications [9]. Recent improvements in the thermal conductivity of polymer composite materials have seen a thermal conductivity in the range of $20 \mathrm{~W} / \mathrm{m}^{2}-\mathrm{K}$ [10]. In addition to the manufacturing advantages offered by such mouldable composites, their relatively low density (around $1000 \mathrm{~kg} / \mathrm{m}^{3}$ as opposed to $2700 \mathrm{~kg} / \mathrm{m}^{3}$ for aluminium) and lower coefficient of thermal expansion $(7 \mathrm{ppm} / \mathrm{K})$ can provide a significant weight reduction and improve the reliability of the converter enclosure [10], [11]. Some applications require exclusive use of polymers because of their unique physical properties: flexibility, low cost, lightweight, corrosion resistance, and ease of manufacturing [6], [12]. In order to dissipate and spread heat, a heatsink material having high thermal conductivity is commonly used. Even though metals are the more promising materials in many applications, in electronic devices where weight is an important factor they are less suitable [13]. Thermally conductive polymers can be broadly 
grouped as either electrically conductive or insulative types, with the former being used in shielding applications [14].

In this work, the heatsink capacitance and heat characteristics are modelled with COMSOL Multiphysics, a finite-element analysis simulation package. The effects on common-mode $(\mathrm{CM})$ noise due to grounding [4], the enclosure as well as device fastening interactions, be it a threaded fastener (metal or nylon) or a spring clamp are investigated. The relevant conducted EMC results from this model, such as parasitic capacitances, are fed into an EMC circuit model. Thermal performance of a polymer heatsink and its impact on conducted noise emissions are investigated. Polymer compound heatsinks is mostly used in low power applications. However, for higher power applications, Silicon Carbide (SiC) devices can be considered as some of these power semiconductor devices do have very high junction operating temperature specifications [11], [15]. Due care needs to be exercised as too high device operating temperatures can lead to gate oxide degradation [16], [17].

Section II A defines the CM and DM equations with respect to the LISN. Section II B deals with the theoretical analysis building an equivalent EMC model showing the noise effects due to the heatsink, extracting transfer functions and impedance plots showing clearly the effect the heatsink have on the circuit. The modelled CM and DM noise plots are also presented. Section II C characterises the heatsink, defining the heatsink capacitance, an important heatsink noise parameter. This is modelled in detail showing effects thereof. Heat spreading simulations are also performed. Section III presents the experimental results, with Section III A presents heatsink impedance measurements, Section III B presenting the noise measurements Section III C presents the thermal conductivity measurements heat effects. Section IV closes with the conclusion. 


\section{THEORETICAL ANALYSIS}

\section{A. Differential- and Common-mode Noise}

The two main conducted noise emission modes that exist in DC-DC power converters are: the differentialmode (DM) and the common-mode of conduction. Differential-mode noise is mainly caused by current flow in the circuit. The propagation path of the DM noise is therefore normally made up of the dc-link and high frequency capacitors, the bus-bars or tracks, and connectors such as threaded terminals and ring lugs. Common-mode noise on the other hand is dictated by the voltage amplitude [4], as well as the time rate-ofchange of the switching signals. The CM noise propagation path is therefore made up mainly of the parasitic capacitances between the bus-bars or PCB tracks and the ground plane as well as the parasitic capacitance between the switching device tab and the heatsink. The switching device in general is electrically separated from the aluminium heatsink by a thin thermally conductive insulating material. Furthermore, the commonmode loop comprises the larger loop-area, making it more prone to noise susceptibility and radiation at higher frequencies [18].

In the current literature, different definitions for CM- and DM-voltages in terms of the noise voltages measured on the dual line impedance stabilising network (LISN) ports do exist. The definitions used in this paper are shown in Fig. 1 (a), and the figure also shows the larger loop area for the CM noise. The commonmode return current is defined as $\mathrm{I}_{\mathrm{CM}}$ and the differential-mode negative line return current defined as $\mathrm{I}_{\mathrm{DM}}$. By applying this nomenclature and with reference to Fig. 1 (a) the following expressions are obtained in terms of the line currents and dual LISN ports $\mathrm{V}_{\mathrm{X}}$ and $\mathrm{V}_{\mathrm{Y}}$ :

$$
I_{D M}=\frac{I_{X}-I_{Y}}{2}
$$

with:

$$
V_{D M}=V_{X}-V_{Y}
$$


The expressions for LISN common-mode current and voltage are similarly obtained as:

$$
I_{C M}=I_{X}+I_{Y}
$$

and

$$
V_{C M}=\frac{V_{X}+V_{Y}}{2}
$$

\section{B. Simplified Converter EMC Noise Modelling}

Simplified circuit models for conducted EMC found in the literature [19], [20] are generally accurate enough to predict conducted noise slopes and to show general trends with accuracy within a few dB. Although not accurate enough for certain aspects of noise modelling, they should be sufficient for the purpose of verifying the heatsink conducted noise effects. A test circuit schematic comprising of a step-down DC-DC converter with a heatsink, power feed-line and a LISN as shown in Fig. 1 (b) is constructed as an example, and can be extended to other converter topologies. The physical layout of the converter and the parasitic effects of concern are indicated in Fig. 1 (c). Two power devices are attached to the heatsink, the MOSFET, Q1, and the diode, D1. A $12 \mathrm{~V}$ sealed lead-acid battery suspended on a wooden block, so as not to influence the noise path, supplies the auxiliary power for the test circuit that comprises of the MOSFET drivers and PWM controllers. Figs. 1 (d) and (e) shows the simplified DM and CM models for the test stepdown DC-DC converter [21]. They are used to discuss and analyse the conducted noise mechanisms due to the heatsink capacitance effect.

The DM model consists of the LISN with two $50 \Omega$ resistors in series representing the LISN impedance, the power feed-line parameters $\mathrm{L}_{\mathrm{LEAD}}$ and $\mathrm{C}_{\mathrm{LEAD}}$, based on the transmission line theory, and the step-down DC-DC converter parameters, $C_{P}, R_{P}$ and $L_{P}$ representing the converter capacitor equivalent impedance. $\mathrm{C}_{\text {TRACE }}$ represents the capacitance between the positive PCB tracks and the negative PCB plane. The current 
source, $\mathrm{I}_{\mathrm{S}}$, represents the trapezoidal switching waveform and the power source with impedance $\mathrm{R}_{\mathrm{DC}}$ is isolated from the noise model by $\mathrm{L}_{\mathrm{LISN}}$.

Similarly, the CM model shows the LISN noise impedance as two parallel $50 \Omega$ resistors, the power feedline to the step-down converter represented by $\mathrm{L}_{\mathrm{LEAD}} / 2, \mathrm{C}_{\mathrm{LEAD}} \mathrm{G}$ the capacitance of the power feed line to the ground plane as well as the ground-plane return inductance $\mathrm{L}_{\mathrm{GND}}$. The power feed line and ground plane parameters were deducted from a series of open- and short-circuited impedance measurements. $\mathrm{C}_{\mathrm{PCB}}$ is the capacitance from the PCB power traces to the heatsink. With reference to the physical layout as in Fig. 1 (c), the converter track inductance, $\mathrm{L}_{\mathrm{PCB}}$, is defined as the series $\mathrm{PCB}$ track inductances consisting of the input to MOSFET drain $\left(\mathrm{L}_{\mathrm{IN}}=40 \mathrm{nH}\right)$, the track between MOSFET source and diode cathode as well as $\mathrm{L}_{1}\left(\mathrm{~L}_{\mathrm{SK}}=20\right.$ $\mathrm{nH})$, between $\mathrm{L}_{1}$ and $\mathrm{R}_{\mathrm{LOAD}}\left(\mathrm{L}_{\mathrm{OUT}}=130 \mathrm{nH}\right)$, paralleled with the negative PCB return plane from $\mathrm{R}_{\mathrm{LOAD}}$ to negative input $\left(\mathrm{L}_{\mathrm{OV}}=100 \mathrm{nH}\right)$. This provides a value of $65 \mathrm{nH}$. The voltage source $\mathrm{V}_{\mathrm{S}}$ represents the trapezoidal switching waveform.

The heatsink capacitance, $\mathrm{C}_{\mathrm{H}}$, is defined as the combined capacitance from the power converter devices and traces, through the heatsink to a ground connection point, creating the common-mode noise path to ground. The main contributing factor to this capacitance is the power components tabs attached to the heatsink by means of threaded fastener or spring loaded clamp, separated by a thin insulating layer. With reference to the physical layout as in Fig. 1 (c), the capacitance from the MOSFET tab to the heatsink is defined as $\mathrm{C}_{\mathrm{HM}}$, and between the diode tab and heatsink it is $\mathrm{C}_{\mathrm{HD}}$. The capacitance between the MOSFET and diode (G-D-S and K-A respectively short circuited) is defined as $\mathrm{C}_{\mathrm{MD}}$. $\mathrm{C}_{\mathrm{H} 0 \mathrm{~V}}$ is the capacitance from the converter negative supply (zero-volt plane) to the heatsink, and $\mathrm{C}_{\mathrm{HC}}$ indicates the heatsink-to-chassis (ground plane) capacitance, in the case where the heatsink is not connected to the chassis.

In the model that will be analysed, the MOSFET and diode are mounted onto the heatsink with stainless steel cheese-head threaded fasteners with a silicone insulating pad in between the device tab and the heatsink. 
On both devices (MOSFET and the diode), the legs are shorted together and used as reference points to be able to determine the relevant capacitances involved in the common-mode noise path. Furthermore, in this case, the heatsink is connected to the chassis $\left(\mathrm{C}_{\mathrm{HC}}=0\right)$, which is in turn connected to earth through $\mathrm{L}_{\mathrm{GND}}$.

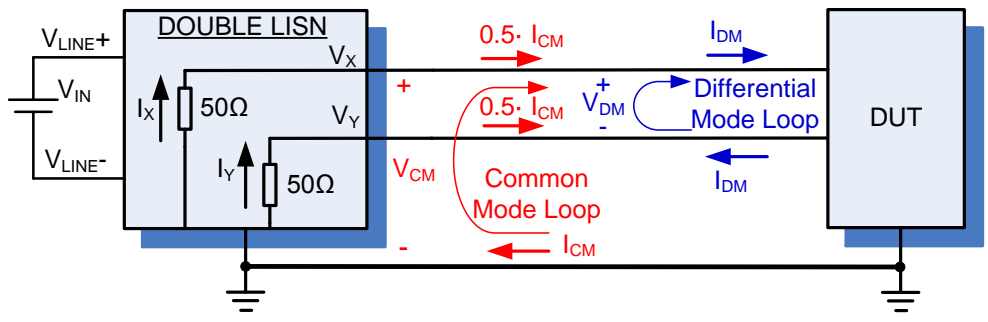

(a)

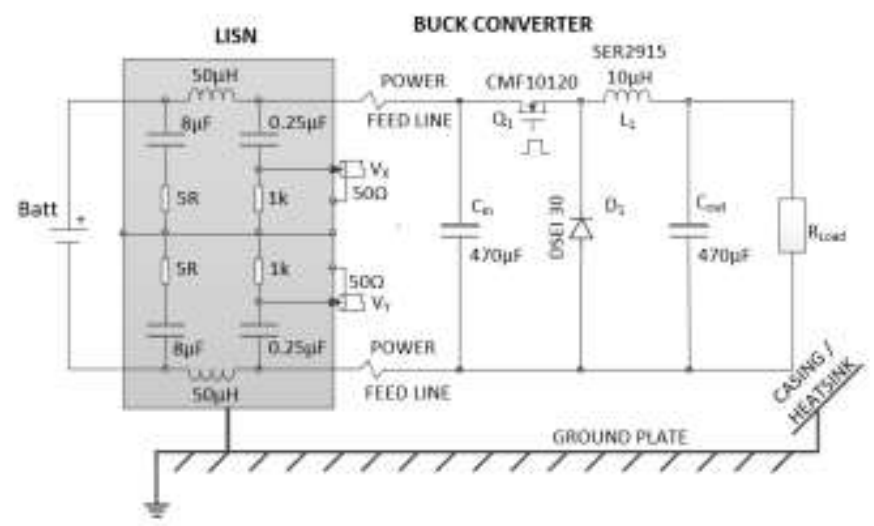

(b)

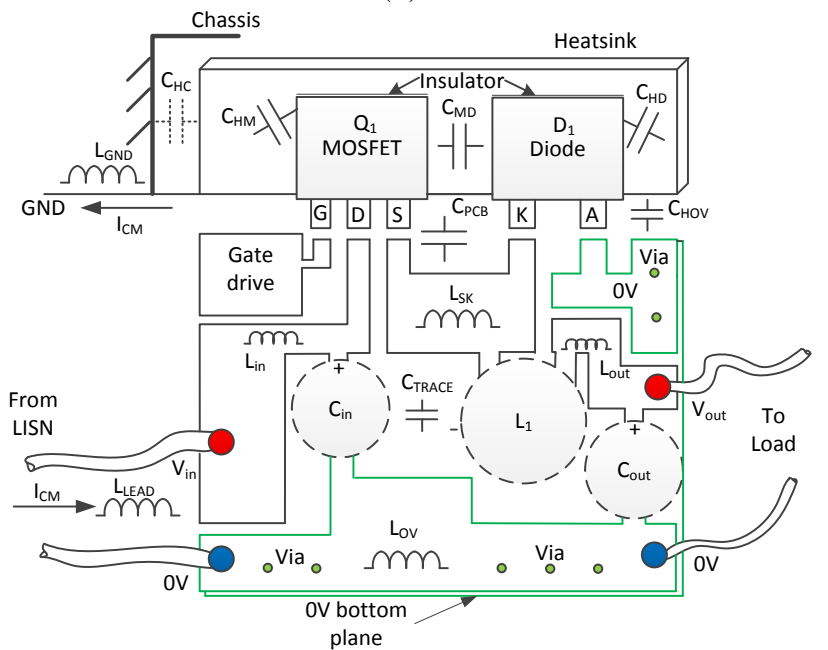

(c) 


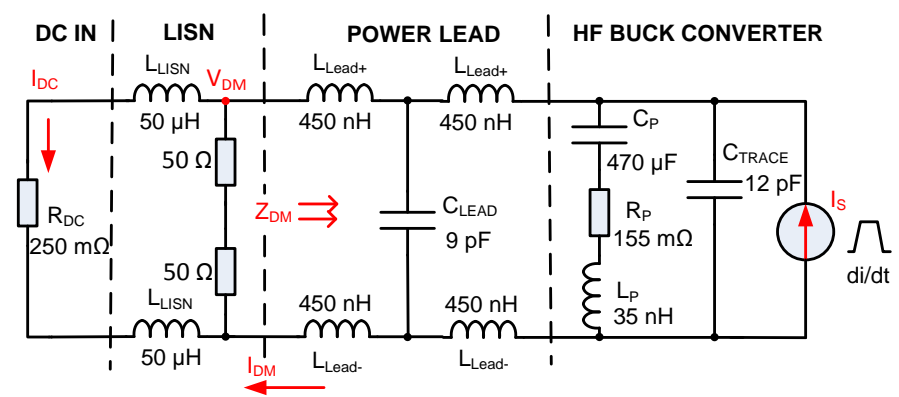

(d)

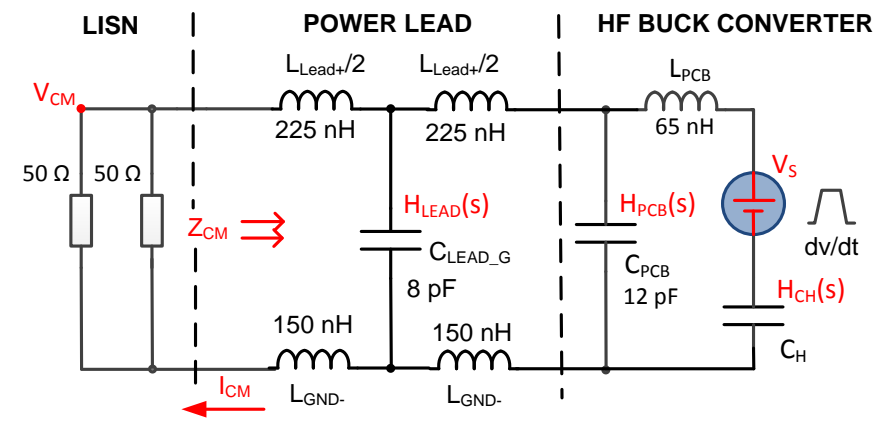

(e)

Fig. 1: (a) Common-mode loop and differential-mode loop defined, (b) step-down converter schematic, (c) step-down converter layout and simplified EMC models (d) DM and (e) CM

Fig. 2 shows a simplified capacitor layout on an aluminium heatsink. The diode switching voltage is $V_{D}$ and the MOSFET switching voltage $\mathrm{V}_{\mathrm{M}}$. The heatsink capacitance to the $0 \mathrm{~V}$ ground plane, $\mathrm{C}_{\mathrm{H} 0 \mathrm{~V}}$ measures $0.9 \mathrm{pF}$. The capacitance, $\mathrm{C}_{\mathrm{H}}$ is all the capacitances combined coupled directly to the heatsink, with $\mathrm{C}_{\mathrm{HC}}$ zero, and is expressed in (5).

$$
C_{H}=\left(C_{H M}+C_{H D}\right)+C_{H 0 V}+C_{H P C B}+\delta_{C M D}
$$

where $\delta_{\mathrm{CMD}}$ is the small contribution due to the capacitance between the switching devices on the heatsink. Considering the noise path from $V_{D}$ through $C_{M D}$ to the heatsink as well as the noise path from $V_{M}$ through $\mathrm{C}_{\mathrm{MD}}$ to the heatsink, $\delta_{\mathrm{CMD}}$ can be expressed as:

$$
\delta_{C M D}=C_{M D} \cdot\left(\frac{C_{H M}}{C_{M D}+C_{H M}}+\frac{C_{H D}}{C_{M D}+C_{H D}}\right)
$$

but with $\mathrm{C}_{\mathrm{MD}} \ll \mathrm{C}_{\mathrm{HD}}$ and $\mathrm{C}_{\mathrm{HM}}$, it can be rewritten as:

$$
\delta_{C M D}=2 \cdot C_{M D}
$$

The heatsink impedance in terms of $\mathrm{C}_{\mathrm{H}}$ can now be expressed as: 


$$
Z_{H}=j\left(\omega\left(L_{G N D}+L_{P C B}\right)-\frac{1}{\omega \cdot C_{H}}\right)
$$

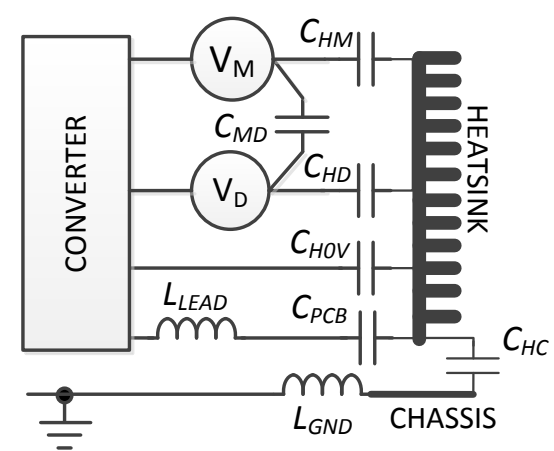

Fig. 2: Physical component layout on a heatsink depicting common-mode parasitics

Referring to the equivalent DM circuit in Fig. 1 (d), the transfer-function $H_{D M}$ of the simplified DM circuit is the ratio of the differential-mode current $I_{D M}$ to the noise source current $I_{S}$ obtained as:

$$
H_{D M}(S)=\frac{I_{D M}(S)}{I_{S}(S)}
$$

Similarly, the transfer-function $H_{C M}$ for the CM circuit in Fig. 1 (e), is the ratio of the common-mode voltage, $\mathrm{V}_{C M}$ to the noise source voltage, $\mathrm{V}_{S}$, obtained as:

$$
H_{C M}(S)=\frac{V_{C M}(S)}{V_{S}(S)}
$$

Replacing the noise source $\mathrm{V}_{\mathrm{S}}(\mathrm{S})$ in the common-mode transfer-function with $\mathrm{VC}_{\mathrm{H}}(\mathrm{S}), \mathrm{VC}_{\mathrm{LEAD}}(\mathrm{S})$ or $\mathrm{VC}_{\mathrm{PCB}}(\mathrm{S})$, creates the transfer functions $\mathrm{H}_{\mathrm{CH}}(\mathrm{s}), \mathrm{H}_{\mathrm{PCB}}(\mathrm{s})$ and $\mathrm{H}_{\mathrm{LEAD}}(\mathrm{s})$ respectively, as defined in Fig. 1 (e). $\mathrm{H}_{\mathrm{CH}}(\mathrm{s})$ is thus defined as the ratio between heatsink capacitance voltage $\mathrm{V}\left(\mathrm{C}_{\mathrm{H}}\right)$ to the common-mode voltage $V_{C M}, H_{P C B}(s)$ the ratio between the PCB capacitance voltage $V\left(C_{P C B}\right)$ to $V_{C M}$ and $H_{L E A D}(s)$ the ratio between the power lead capacitance voltage $\mathrm{V}\left(\mathrm{C}_{\mathrm{Lead}}\right)$ to $\mathrm{V}_{\mathrm{CM}}$. These are a measure of the influence a given branch will have on the common-mode voltage over a given frequency range. The common-mode transfer functions and their magnitudes are evaluated from $10 \mathrm{kHz}$ to $200 \mathrm{MHz}$, and are presented in Fig. 3 (a). The transferfunction due to the heatsink capacitance $\mathrm{C}_{\mathrm{H}}\left(\mathrm{H}_{\mathrm{CH}}(\mathrm{s})\right)$, is dominant in the lower frequency band, below 20 
MHz. Beyond $20 \mathrm{MHz}$, the capacitance $\mathrm{C}_{\mathrm{PCB}}$ becomes more prominent and at around $90 \mathrm{MHz}$, the power lead capacitance $\mathrm{C}_{\mathrm{LEAD}}$ tends to become dominant.

The differential- and common-mode impedance is calculated and plotted for two values of $\mathrm{C}_{\mathrm{H}}$ as shown in Fig. 3 (b). The common-mode noise advantage of higher conducted emission impedance due to $\mathrm{C}_{\mathrm{H}}$ is shown to be below $20 \mathrm{MHz}$. The differential-mode impedance is seen not influenced by the change in heatsink capacitance. Fig. 3 (c) shows the effect when $L_{G N D}$ is reduced, showing a common-mode noise advantage beyond $10 \mathrm{MHz}$. The common- and differential-mode noise spectrum plots are obtained from the models and presented in Figs. 3 (d) and (e) respectively, compared against the MIL-STD-461F limit as a reference. The switching signal is modelled with a period of $10 \mu \mathrm{s}$ (100 kHz switching frequency) and a duty cycle of $50 \%$. The rise- and fall-times are $100 \mathrm{~ns}$.

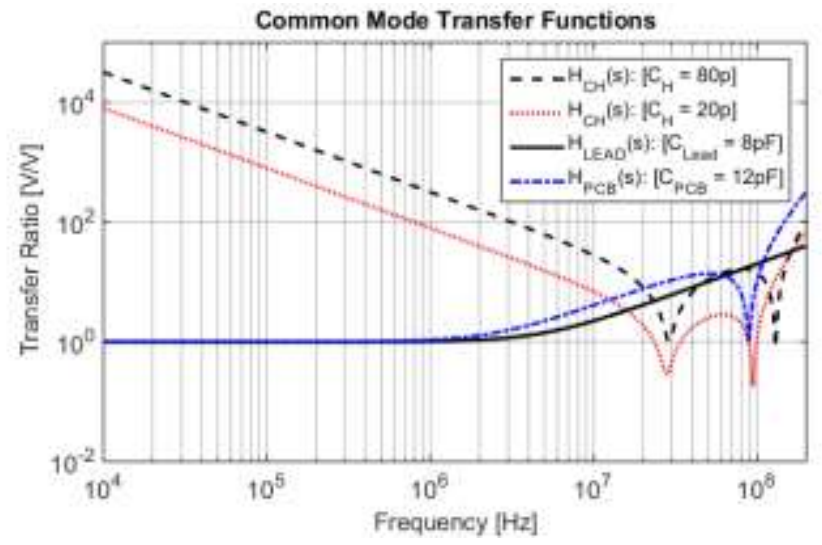

(a)

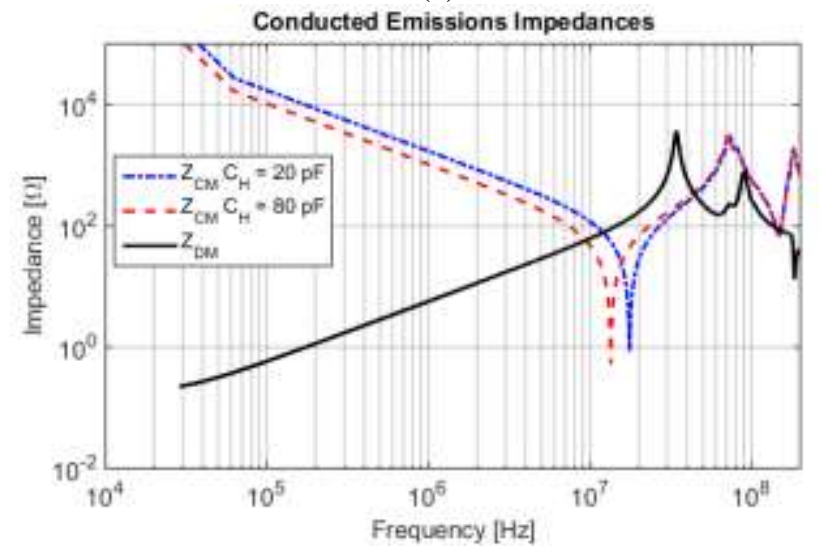

(b) 


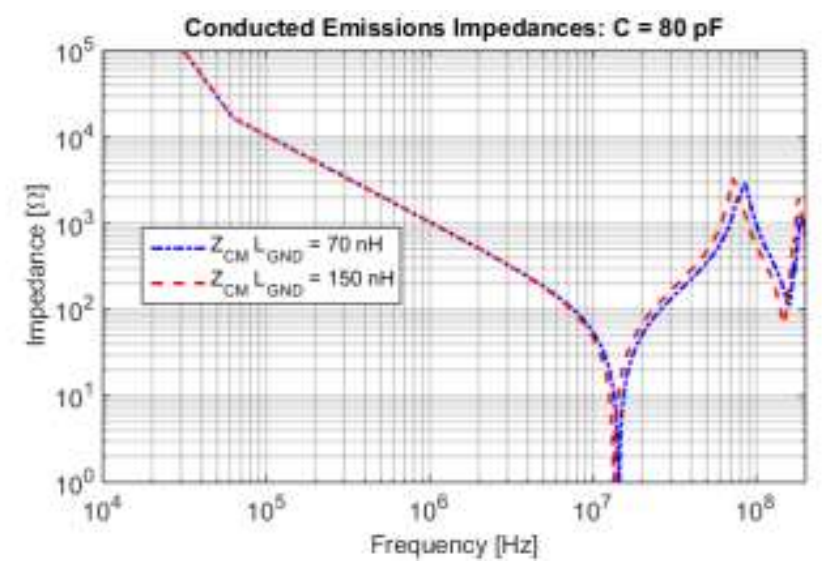

(b)

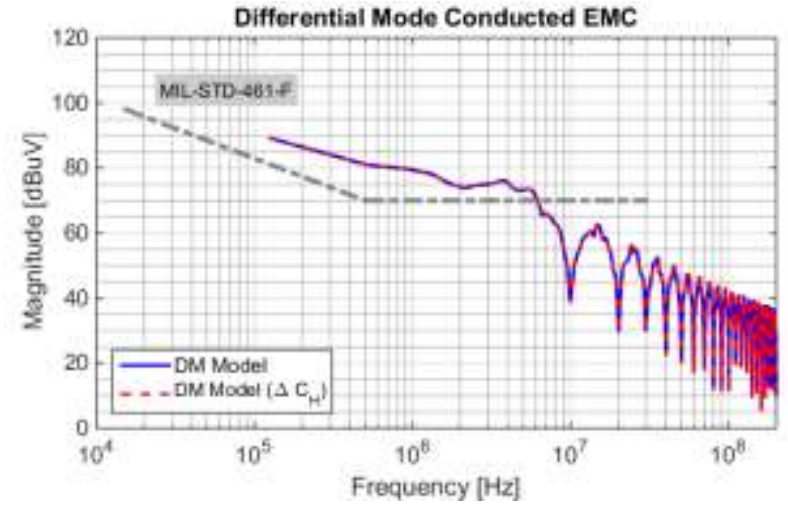

(d)

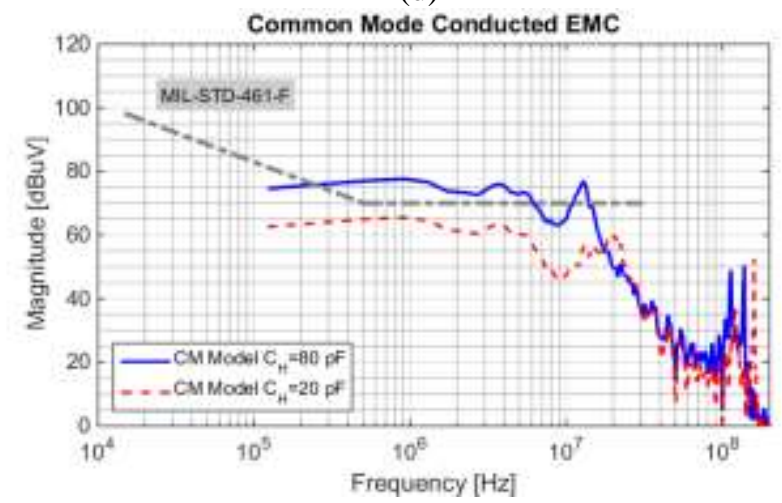

(e)

Fig. 3: (a) Common-mode transfer-functions, (b) DM and CM impedance for two different heatsink capacitances, (c) changing value $\mathrm{L}_{\mathrm{GND}}$, (c) and (d) $\mathrm{DM}$ spectral plot up to $200 \mathrm{MHz}$ and (e) $\mathrm{CM}$ spectral plot for $\mathrm{C}_{\mathrm{H}}=80 \mathrm{pF}$ and $20 \mathrm{pF}$.

\section{Heatsink Characterisation}

The models show that the DM noise is not influenced by the total heatsink capacitance $\mathrm{C}_{\mathrm{H}}$, which however influences the CM noise signal. Consequently, to be able to accurately determine the CM noise, the total heatsink capacitance, $\mathrm{C}_{\mathrm{H}}$, should be correctly analysed and determined. 
The device tab capacitance-to-ground plays a very important role in both the generation and propagation of the common-mode noise. It can be estimated using the parallel-plate capacitance expression for $C_{\text {Plate }}$ as given in (11):

$$
C_{\text {Plate }}=\frac{\varepsilon_{0} \varepsilon_{r} A}{d}
$$

where $A$ is the area of the MOSFET tab and $d$ the SILPAD insulator thickness taken as $0.152 \mathrm{~mm}, \varepsilon_{0}$ is the permittivity of air and $\varepsilon_{\mathrm{r}}$ the permittivity of the heatsink insulator taken as $2.9 \mathrm{~F} / \mathrm{m}$. If the standard sized TO247 metal tab (14 mm x $16 \mathrm{~mm}$ ) data are substituted into (11), the capacitance for a single device works out as $38.3 \mathrm{pF}$.

A TO-247 package on an aluminium block $0.5 \mathrm{~cm}$ think, a width of $3 \mathrm{~cm}$ and a depth of $3 \mathrm{~cm}$ is modelled in COMSOL, as shown in Fig. 4 (a) to determine the heatsink parasitics. The metal enclosure around the model in Fig. 4 (a) is a variable, incremented in steps from an initial size of $5 \mathrm{~cm}$ wide, $5 \mathrm{~cm}$ deep and a height of $2.5 \mathrm{~cm}$, to final width of $13 \mathrm{~cm}$, depth of $13 \mathrm{~cm}$ and a height of $6.5 \mathrm{~cm}$. This is done in order to model the enclosure proximity effects on the devices to the heatsink capacitance. The same enclosure is modelled in two modes: when the metal enclosure is at a floating potential and also when the metal enclosure is connected to earth. The polymer material is chosen from the library, with relative permeability $\varepsilon_{\mathrm{r}}$ $=4$ and density of $1150 \mathrm{~kg} / \mathrm{m}^{3}$.

The COMSOL model graphical results showing the normalised electrical field plot in Fig. 4 (b), illustrates the influence of the threaded fastener, with capacitance fringing fields visible in the electric field plot. Figs. 4 (c) and (d) show the model setup presenting the electric potential for aluminium and polymer heatsinks respectively at $100 \mathrm{~V}$. These models are less detailed and are used to analyse different materials and compounds for comparison purposes in heatsink applications. 
Figs. 4 (e) and (f) show the capacitance plots for aluminium and polymer heatsinks respectively. In both cases they illustrate the slight differences in capacitance due to the two enclosure modes. When the metal enclosure is grounded, the capacitance starts off slightly higher compared to the case where the enclosure is floating. As the enclosure around the device increases in size, the heatsink capacitance converges to an average of $39.4 \mathrm{pF}$ for the aluminium heatsink. This is slightly higher than the calculated parallel-plate capacitance, $\mathrm{C}_{\text {Plate, }}$ of $38.3 \mathrm{pF}$. The increase is predominantly due to the fringing effects as well as the threaded fastener effects, and demonstrates the importance of including other effects on devices to ground capacitance. Moreover, it is seen that device-to-ground capacitance is also influenced by the size of the metal enclosure. By replacing the stainless steel threaded mounting fasteners on the power devices with nylon ones, the capacitance decreases by $1.2 \mathrm{pF}$. On the other hand, securing the devices with a spring loaded metal clamp instead of stainless steel cheese-head threaded fasteners lowered the capacitance by another $0.7 \mathrm{pF}$. A further reduction in device-to-ground through heatsink capacitance is achieved by introducing polymer heatsink material. From Fig. 4 (f), it is seen that this causes capacitance on average to decrease from $39.4 \mathrm{pF}$ to $3.8 \mathrm{pF}$ measured from the tab through the heatsink to a ground plane for a single power device.

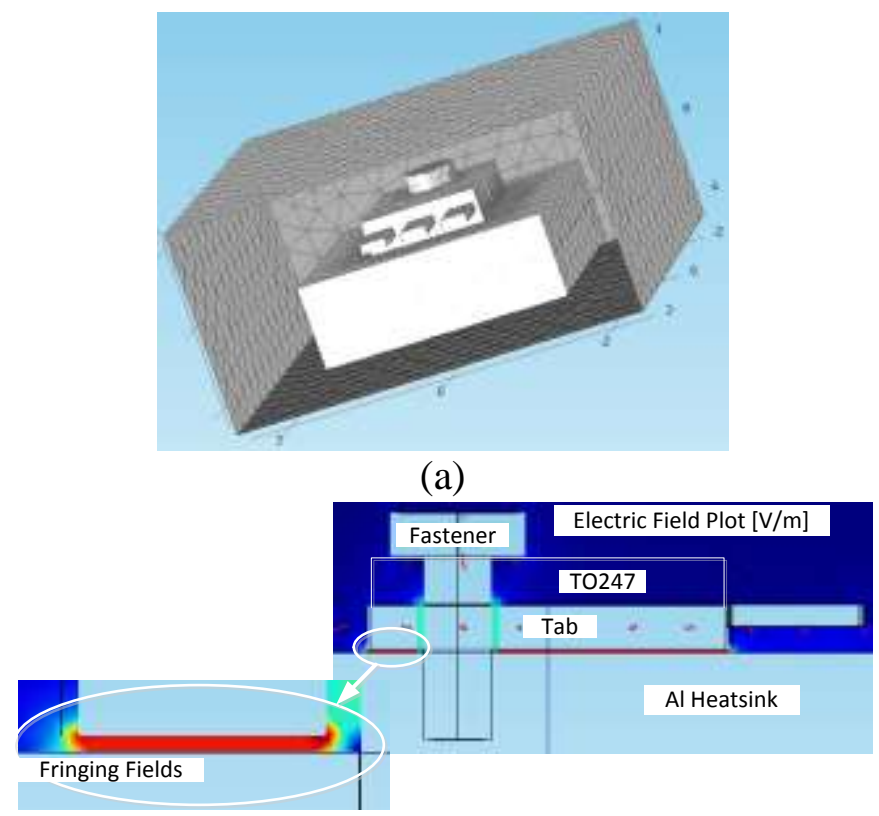


(b)

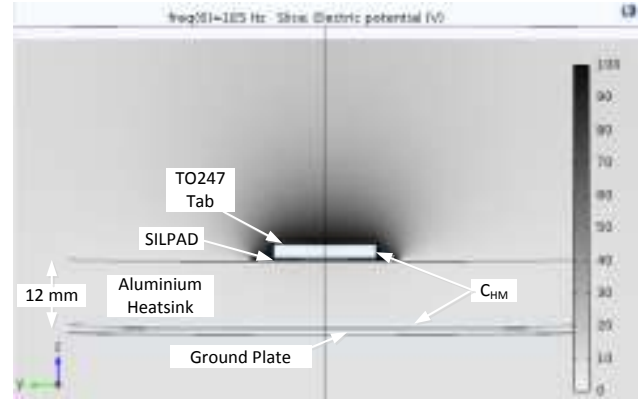

(c)

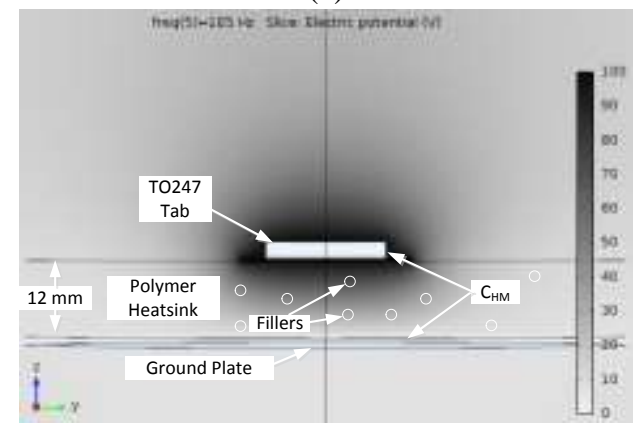

(d)

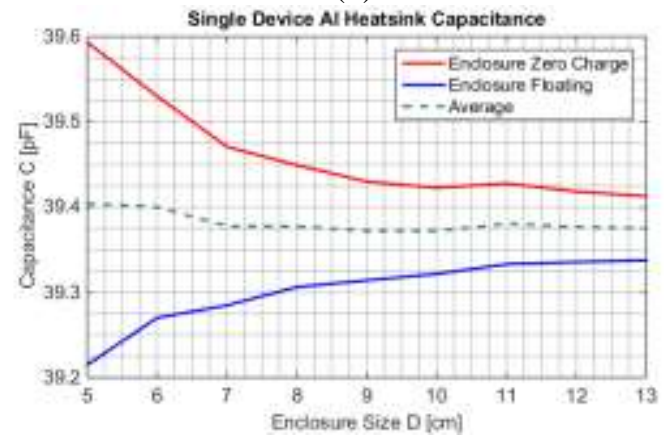

(e)

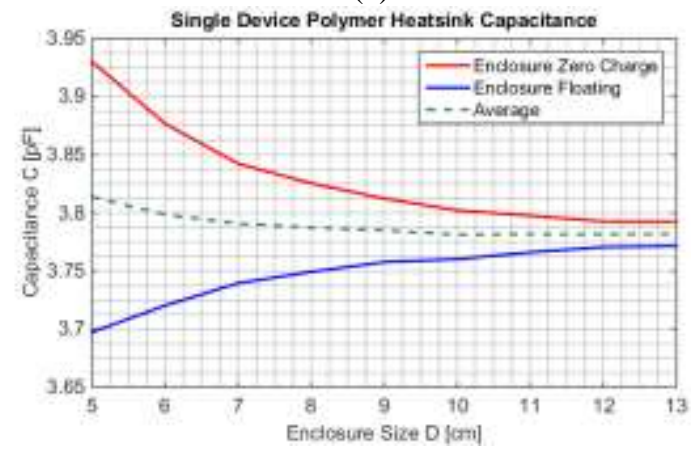

(f)

Fig. 4: (a) COMSOL single device heatsink capacitor model with stainless steel threaded fastener, (b) the normalised modelled electric field plot, (c) aluminium and (d) polymer device capacitance model, (e) the aluminium heatsink capacitance and (f) the plain polymer heatsink capacitance

The heat capacity of a polymer without any heat conducting fillers is not adequate for practical heat spreader application, and need to be added thereby increasing the heat capacity as well as the capacitance. 
Fillers can be included in various ways, in sandwiched layers or in powder form. Modelling the polymer compound as $60 \% \mathrm{Cu}$ sandwich layers, increased the overall heatsink capacitance to chassis by $6.1 \mathrm{pF}$.

Fig. 5 (a) shows the temperature distribution in an aluminium heatsink test block, $70 \mathrm{~mm} \times 70 \mathrm{~mm} \times 10$ $\mathrm{mm}$, and a TO247 device dissipating $1 \mathrm{~W}$. The room temperature was set to $20^{\circ} \mathrm{C}$. A SILPAD insulator of $0.152 \mathrm{~mm}$ separates the TO247 device from the heatsink, and has a thermal resistance of $1.3{ }^{\circ} \mathrm{C} / \mathrm{W}$. The temperature on the die increased to $33.5^{\circ} \mathrm{C}$. Replacing the aluminium heatsink with a polymer without any filler material, the die temperature rises to an incredible $138.9^{\circ} \mathrm{C}$. Adding only $25 \%$ copper filler, reduces the die temperature to $61.2^{\circ} \mathrm{C}$. With $60 \%$ copper filler as shown in Fig. 5 (b), the modelled die temperature reduces even further to $42.3{ }^{\circ} \mathrm{C}$.

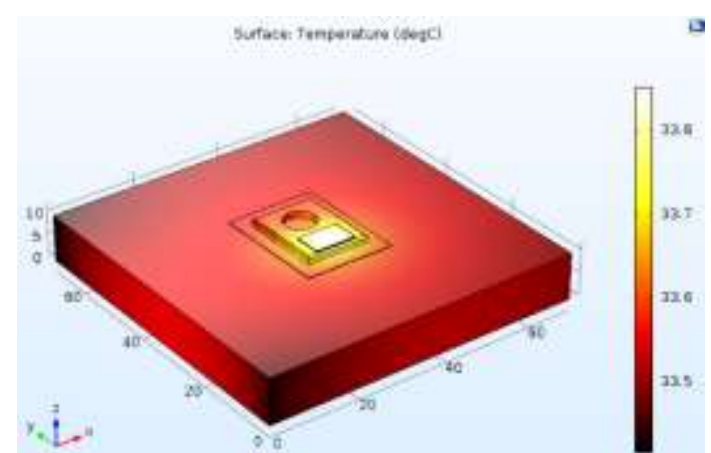

(a)

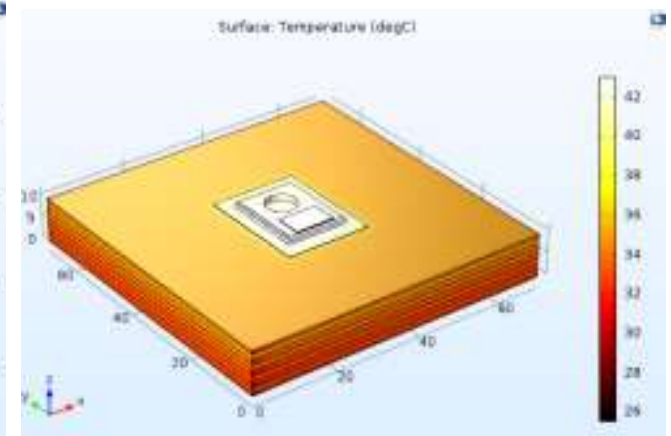

(b)

Fig. 5: (a) Temperature distribution in aluminium (b) in Polymer with $60 \% \mathrm{Cu}$ filler

\section{EXPERIMENTS AND RESULTS}

A series of measurements are performed to validate the theoretical analysis. Heatsink blocks were manufactured and moulded into a standard $70 \mathrm{~mm}$ x $60 \mathrm{~mm}$ x $10 \mathrm{~mm}$ forms. Two base materials are used for the experiments, an epoxy resin EpoxAcast 690 and a F19 Urethane Resin. The heat conducting filler is a copper powder compound consisting of a particle size varying between $80 \mu \mathrm{m}$ and $100 \mu \mathrm{m}$ for increased particle packing density. The plastic heatsink mixing table is given in Table 1. The maximum copper particle composite mixture by weight achieved is $65 \%$ for polyurethane and $82 \%$ for epoxy. A similar sized aluminium heatsink, composite 6082 alloy, is used as a reference. 
Table 1: Plastic Heatsink Mixing Table

\begin{tabular}{|c|c|c|c|c|}
\hline Parameter & $\begin{array}{l}\text { EpoxAcast } 690 \\
\text { Reference }\end{array}$ & $\begin{array}{l}\text { EpoxAcast } 690 \\
\text { Cu Filler } 82 \%\end{array}$ & $\begin{array}{l}\text { F19 Urethane } \\
\text { Resin Reference }\end{array}$ & $\begin{array}{l}\text { F19 Urethane Cu } \\
\text { Filler } 64 \%\end{array}$ \\
\hline Length [cm] & 7.00 & 7.00 & 7.00 & 7.00 \\
\hline Width [cm] & 5.95 & 5.95 & 5.95 & 5.95 \\
\hline Thickness [cm] (Average) & 0.9 & 0.9 & 1.0 & 0.8 \\
\hline Volume $\left[\mathrm{cm}^{3}\right]$ & 37.49 & 37.49 & 41.65 & 33.32 \\
\hline Measured Mass [g] & 43.25 & 232.35 & 43.65 & 103.92 \\
\hline Resin Mass [g] & 41.23 & 41.23 & 43.32 & 36.65 \\
\hline Resin Density $\left[\mathrm{g} / \mathrm{cm}^{3}\right]$ & 1.10 & 1.10 & 1.04 & 1.04 \\
\hline Filler Mass [g] & - & 191.12 & - & 67.27 \\
\hline Filler \% (Mass) & - & 82.25 & - & 64.73 \\
\hline Copper Density [g/cm3] & - & 8.96 & - & 8.96 \\
\hline Mass if Solid Copper [g] & - & 335.86 & - & 298.547 \\
\hline
\end{tabular}

The effects of polymer heatsinks on common-mode noise is investigated using a MIL-STD-461F based measurement setup. A small high-frequency $50 \mu \mathrm{H} / 50 \Omega$ ring-core LISN calibrated up to $100 \mathrm{MHz}$ [22] and earthed copper sheet bench setup, according to MIL-STD-461-F specifications [23], are manufactured and implemented to verify all simulated data. Time-domain broadband conducted EMC measurements are recorded with a Tektronix MDO4034B oscilloscope with four 11-bit analogue channels at $2.5 \mathrm{GS} / \mathrm{s}$. MATLAB is used as a digital signal-processing tool for analysing the recorded data and calculating the spectral slopes [24]. Furthermore, common-mode and differential-mode noise signals are digitally separated from the LISN measurements [22]. The thermal image measurements are performed with a Fluke Thermal Imager, model Ti10. For more accurate temperature readings determining thermal conductivity, a Fluke 87 with a temperature probe is used. The impedance measurements are performed with an HP4192 LF Impedance Analyser up to $13 \mathrm{MHz}$ and complemented with an HP8753 Network Analyser up to $100 \mathrm{MHz}$ and beyond. Experiments will be performed on a $120 \mathrm{~W}$ step-down DC-DC converter tested in a MIL-STD$461 \mathrm{~F}$ test environment [23]. 
Also not to be ignored is the important assembly procedure when tightening a device onto the heatsink. A 0.7 N-m torque setting is used on the nylon threaded fastener to guarantee consistency in all measurements carried out. Devices are mounted with a thin layer of white heat-paste. Heat transfer characteristics will also be measured.

\section{A. Device Heatsink Impedance Properties}

The constructed heatsinks are placed on a conductive ground sheet and heatsink capacitances are measured. Aluminium heatsink capacitances measurements are shown in Fig. 6 (a), as performed with the impedance analyser. Each semiconductor device (diode and MOSFET) measured $40 \mathrm{pF}$ to the ground plane, giving a total of $80 \mathrm{pF}$. The Stainless steel threaded fastener added $2.2 \mathrm{pF}$ to the device-to-ground capacitance. The measured capacitance between the two devices is about $0.7 \mathrm{pF}$.

The high frequency test setup and impedance plot for all applicable heatsink materials are performed with the impedance analyser and network analyser combined. The test setup is shown in Fig. 6 (b). It consists of the device, fastened with a nylon threaded fastener to the heatsink and a small ground plane acting as the reference earth. The measurement is taken between the reference earth and the shortened device legs soldered together which in turn is attached to the device tab. The heatsink to be analysed is sandwiched in between. The results in Fig. 6 (c) provide information about high frequency resonant effects as well as inductive effects that might occur in the $100 \mathrm{MHz}$ measurement band. A summary of the capacitances and permittivity measured are given in Table 2.

The polyurethane as well as the epoxy materials shows an increase in capacitance (permittivity) from 2.15 $\mathrm{pF}$ to $4.37 \mathrm{pF}$ for polyurethane consisting of $65 \%$ copper powder filler and from $2.93 \mathrm{pF}$ to $7.07 \mathrm{pF}$ for epoxy base material consisting of $82 \%$ copper powder filler. This suggests that it is possible to significantly attenuate the common-mode noise (lowering the device-to-ground capacitance and hence increasing path impedance) using these thermal solutions. 


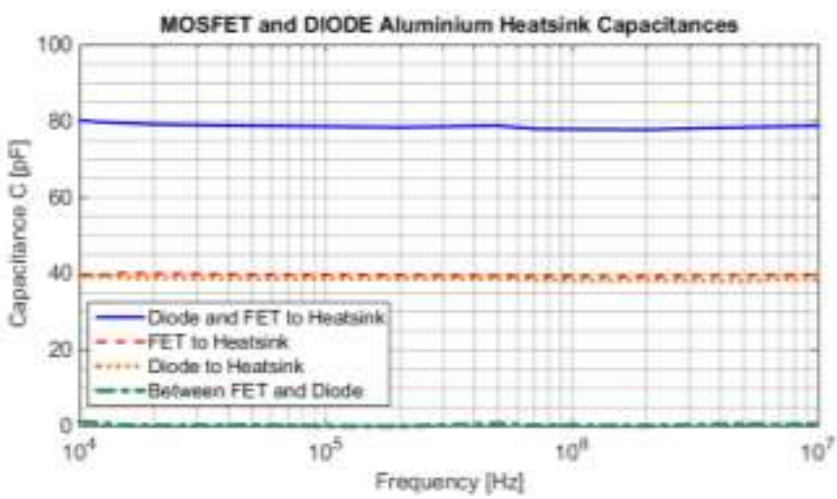

(a)

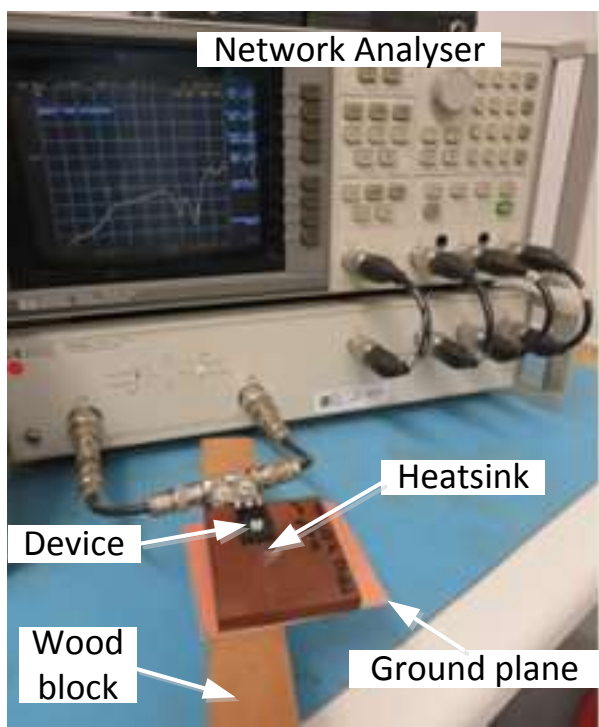

(b)

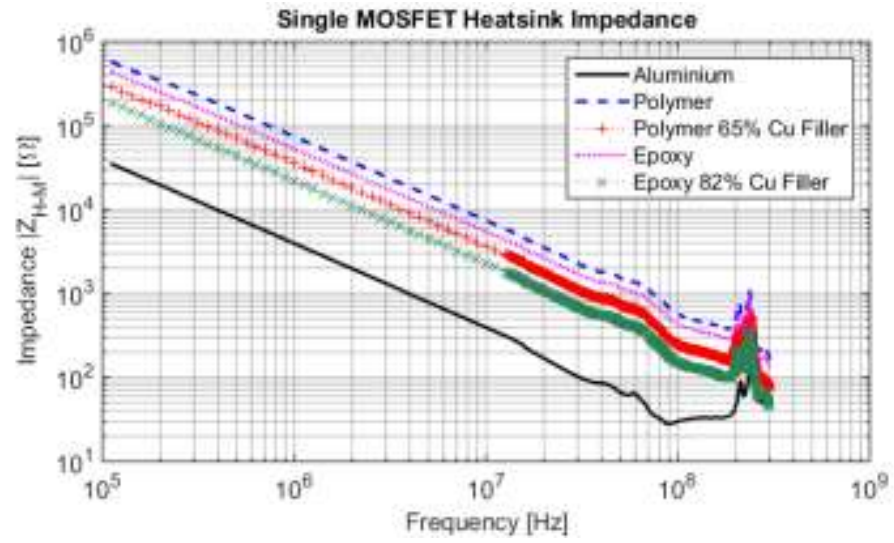

(c)

Fig. 6: (a) Device aluminium heatsink capacitances from $10 \mathrm{kHz}$ to $13 \mathrm{MHz}$, (b) the measurement setup and (c) the full spectrum aluminium and polymer impedance plots 
Fig. 7 (a) presents the common-mode impedance for both the aluminium and the polymer heatsinks as measured with an impedance analyser from the LISN looking towards the step-down converter, LISN disconnected, as indicated in Figs. 1 (d) and (e) validating the calculated model impedance in Fig. 3. (b), comparing both, showing a good agreement to the model. Fig. 7 (b) shows the $\mathrm{V}_{\mathrm{X}}$ LISN port conducted emission noise spectrum from $10 \mathrm{kHz}$ to $200 \mathrm{MHz}$. The $\mathrm{V}_{\mathrm{X}}$ port noise is a combination of differential- and common-mode noise, and from (2) and (4) it is obtained as:

$$
V_{X}=\frac{V_{D M}+2 V_{C M}}{2}
$$

In the case of the test step-down converter, the polymer heatsink common-mode noise advantage can be deduced from the port $\mathrm{V}_{\mathrm{X}}$ characteristics on the dual LISN between $1 \mathrm{MHz}$ and $30 \mathrm{MHz}$. Fig. 7 (c) shows the measured differential-mode noise spectrum, and as predicted from the theory, using polymer heatsinks as opposed to aluminium has no significant effect across the measurement frequency band. The common-mode noise spectrum, presented in Fig. 7 (d) shows a good reduction in common-mode noise (10-15 dB) up to 30 MHz. As predicted, beyond $30 \mathrm{MHz}$ the common-mode reduction due to heatsink capacitance $\mathrm{C}_{\mathrm{H}}$ to ground has almost no effect as other parasitic effects becomes more prominent. This graph is also in good agreement with the theory. 


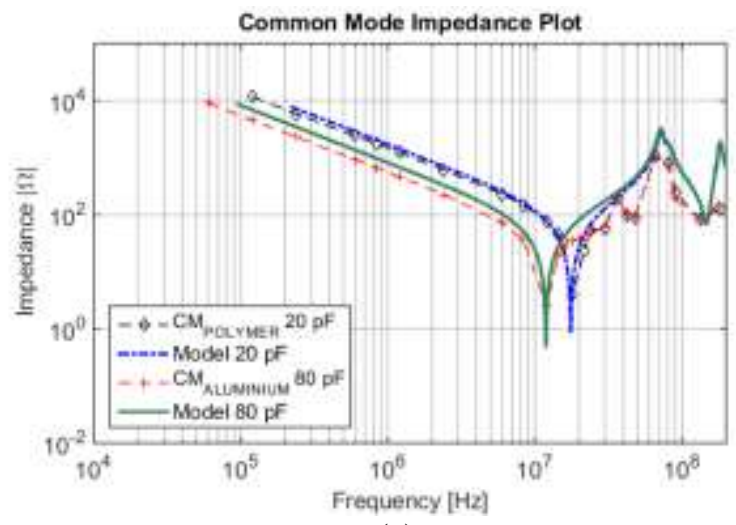

(a)

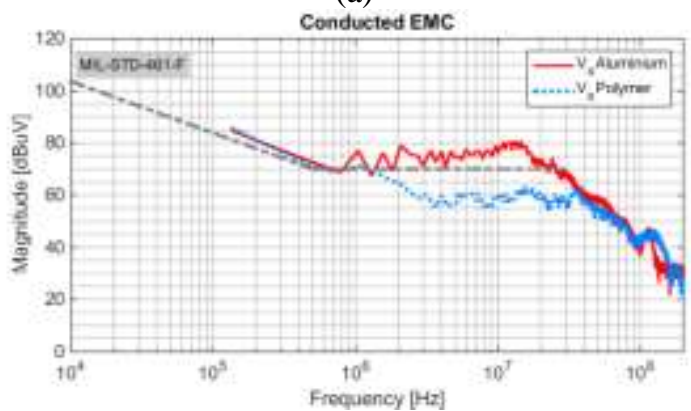

(b)

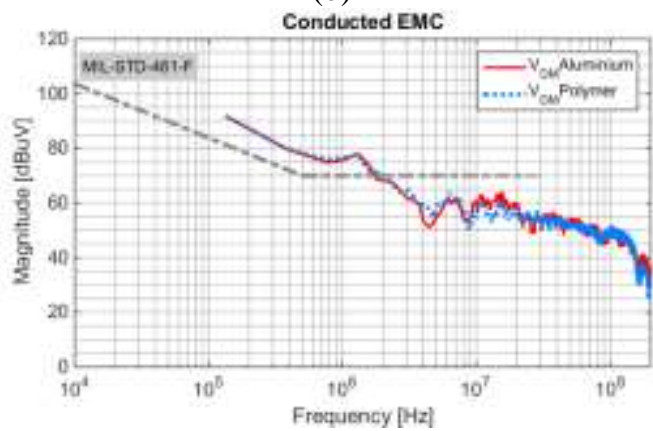

(c)

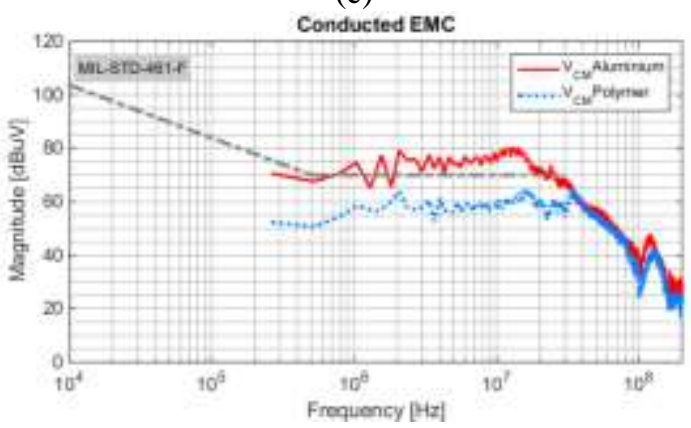

(d)

Fig. 7: (a) CM impedance measurement compared to model, (b) polymer composite heatsink effect on LISN Vx port, (c) differential-mode noise and (d) common-mode noise 


\section{Polymer Heatsink Temperature Effects}

To be able to quantify thermal performance, the thermal conductivity needs to be defined. For a heatsink, $k$ in $\left[\mathrm{W} / \mathrm{m}^{2}-\mathrm{k}\right]$, is the ability of the material to conduct heat [25], and is given in (13).

$$
k=\frac{q}{A \cdot \Delta T}
$$

Referring to (13), $q$ is the heat flux or amount of heat transferred through the material [W], $A$ the heatsink area $\left[\mathrm{m}^{2}\right]$ and $\Delta T$ the temperature delta between the ambient temperature and the average heatsink temperature $[\mathrm{K}]$. Hence, a higher value of $k$ means better performance.

The temperature measurements were performed at an ambient temperature of $20{ }^{\circ} \mathrm{C}$. A T0247 device dissipating about $1 \mathrm{~W}$ is fastened to the heatsink under test with a nylon threaded fastener. The heatsink is placed on a wooden block, and natural convection takes place. After 1 hour, the temperatures for different materials were measured with an infra-red camera. The values are used to give approximate thermal conductivity values for materials comparison purposes. Only the aluminium heatsink has an insulator pad. A thin layer of heatsink paste is used in all instances. Table 2 provides a summary of the quantitative thermal performance value compared to the heatsink capacitances measured previously. The aluminium heatsink has a clear thermal performance advantage, but shows a poor capacitance to ground value.

Three heatsink temperature readings are taken with a thermocouple and averaged [25]. Populating (13) with all known values provides the thermal conductivity, listed in Table 2. 
Table 2: Heatsink material properties.

\begin{tabular}{|l|c|c|c|c|c|}
\hline $\begin{array}{c}\text { Base Material (10 } \\
\text { mm thickness) }\end{array}$ & $\begin{array}{c}\text { TO-247 } \\
\text { Capacitance to } \\
\mathbf{G N D} \\
{[\mathbf{p F}]}\end{array}$ & $\begin{array}{c}\text { Relative } \\
\text { Permittivity } \\
{[\mathbf{F} / \boldsymbol{m}]}\end{array}$ & $\begin{array}{c}\text { Average case } \\
\text { Temperature } \\
{\left[{ }^{\circ} \mathbf{C}\right]}\end{array}$ & $\begin{array}{c}\text { Average } \\
\text { Heatsink } \\
\text { Temperature } \\
{\left[{ }^{\circ} \mathbf{C}\right]}\end{array}$ & $\begin{array}{c}\text { Thermal } \\
\text { Conductivity } \\
{\left[\mathbf{W} / \boldsymbol{m}^{2}-\boldsymbol{K}\right]}\end{array}$ \\
\hline $\begin{array}{l}\text { Aluminium with } \\
\text { silpad insulator }\end{array}$ & $40.0 \mathrm{pF}$ & 2.9 (SILPAD) & 36.7 & 31.3 & 30.6 \\
\hline $\begin{array}{l}\text { Poly-urethane } \\
\text { base, no filler }\end{array}$ & $2.15 \mathrm{pF}$ & 2.7 & 54.7 & 24.8 & 13.1 \\
\hline $\begin{array}{l}\text { Poly-Urethane, } \\
\text { 65\% Cu powder }\end{array}$ & $4.37 \mathrm{pF}$ & 5.4 & 47.6 & 28.0 & 16.5 \\
\hline $\begin{array}{l}\text { Epoxy base, no } \\
\text { filler }\end{array}$ & $2.93 \mathrm{pF}$ & 3.61 & 53.6 & 25.0 & 12.7 \\
\hline $\begin{array}{l}\text { Epoxy, 82\% Cu } \\
\text { powder }\end{array}$ & $7.07 \mathrm{pF}$ & 8.73 & 41.2 & 29.8 & 21.2 \\
\hline
\end{tabular}

The downside to polymer heatsinks managing heat transfer is that due to lower thermal performance from [10] and also seen in above experiments, higher case temperatures need to be tolerated. The thermal conductivity of aluminium was measured at $30.6 \mathrm{~W} / \mathrm{m}^{2-} \mathrm{K}$, close to the value as measured in [25] with similar sized block. The bare polyurethane and epoxy heatsinks show a thermal conductivity of about 3 times less than that of aluminium, but adding heat conductive filler, such as fine copper powder, reduced the heat conductivity to less than 2 times compared to aluminium. Approximately $10^{\circ} \mathrm{C}$ difference in temperature is observed when comparing measurements of an aluminium heatsink with those of a similar sized epoxy composite heatsink at $1 \mathrm{~W}$ device dissipation, confirmed as shown with the thermal camera in Figs. 8 (a) and (b). This result compares well with the COMSOL model results in Figs. 5 (a) and (b), where a $60 \%$ sandwiched copper filler model raised the die temperature to $42.3^{\circ} \mathrm{C}$. Fig. 8 (c) shows the polymer heatsink temperature effect with no filler material, raising the temperature to $53.6{ }^{\circ} \mathrm{C}$, much lower than the simulated temperature due to measurements performed on the casing instead of the die. Converting the temperature values back to a $120 \mathrm{~W}$ converter using the thermal conductivity readings in Table 2, and conversion efficiency at $96 \%$ with about $5 \mathrm{~W}$ device losses to be dissipated by the heatsink, the aluminium block will have an expected case temperature of $75{ }^{\circ} \mathrm{C}$. Replacing with an epoxy block having $82 \%$ copper powder filler, this temperature will raise to $102^{\circ} \mathrm{C}$. From the Vishay application note [26], the die temperature will be 
approximately $7.4 \%$ higher than the surface temperature, thus expected maximum die temperature is $109^{\circ} \mathrm{C}$. This is still within the operating capability of the MOSFET, but de-rating curves apply. In Fig. 8 (d) an example of a converter product employing polymer materials and utilised in a military environment is shown. It is a $60 \mathrm{~W}$ ruggedised IP68 solar panel switch-mode regulator encapsulated by a heat conductive injection moulded polymer, which passed the stringent MIL-STD-461F conducted emission tests as well as all the shock and vibration tests imposed on the design.

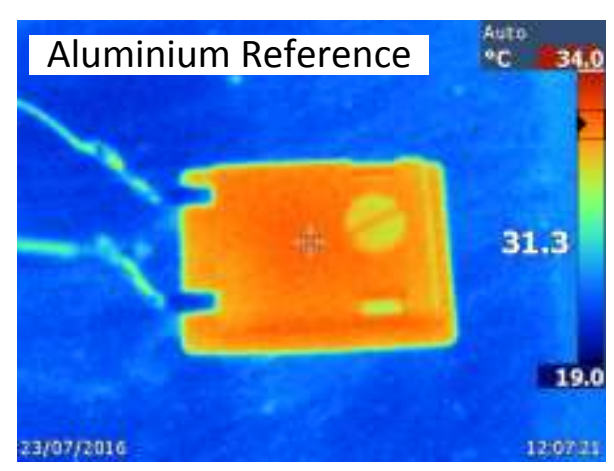

(a)

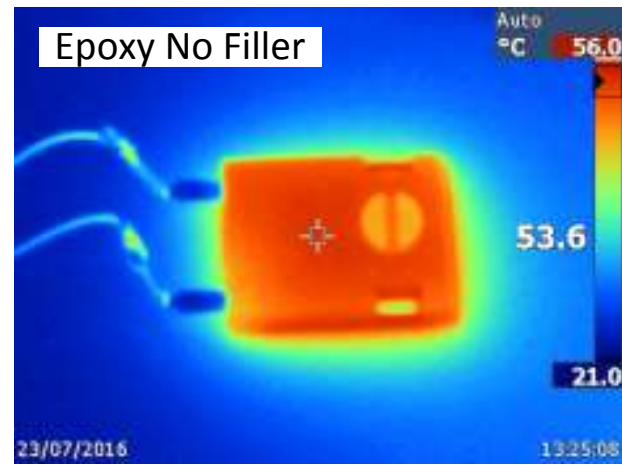

(c)

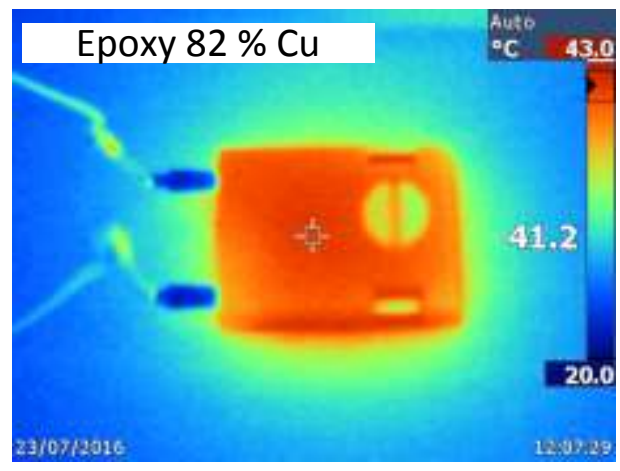

(b)

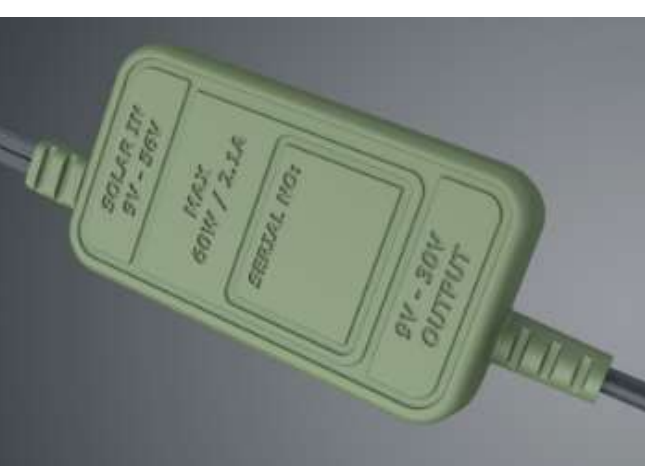

(d)

Fig. 8: Temperature measurement between aluminium (a) Epoxy $82 \% \mathrm{Cu}$ filler (c) no filler material and (d) thermal polymer packaged product.

\section{Conclusion}

Conducted EMC modelling of a test step-down DC-DC converter and subsequent measurements were performed based on the MIL-STD-461F requirement, calibrated to $100 \mathrm{MHz}$, to investigate the effects on common-mode and differential-mode noise of polymer heatsinks as compared to aluminium. Conducted emission models were created and used to determine the effects of different materials on device heatsink 
capacitance to ground. The common-mode capacitances and the important role the heatsink plays on common-mode noise is highlighted and analysed. A COMSOL model was created to verify the capacitance as well as modelling secondary effects such as the stainless steel threaded fasteners, device clamps, etc., that might have an influence on heatsink capacitance. A heatsink block was modelled in COMSOL, and the material changed from aluminium to polymers, in all cases recording capacitances and temperature distribution effects. The polymer heatsinks yielded much lower capacitance to earth and hence CM noise values. Furthermore, it was seen that the stainless steel threaded fastener contributes $2.2 \mathrm{pF}$ to the TO-247 package heatsink capacitance. Using polymer instead of aluminium to heatsink material yields a substantial reduction in common-mode noise within the conducted emission band up to $30 \mathrm{MHz}$. No noticeable effect on differential-mode noise was seen over the frequency band. Heat conductive fillers need to be added to polymers to increase the heat capacity. However, it was shown that the capacitances did increase as a result, although they were still significantly lower than when using aluminium heatsinks. Due to lower heatsink capacitance, smaller sized common-mode EMI filters can be implemented, reducing the overall size of the converter. The advantage of polymer heatsinks can be extended to other converter topologies.

The manufacturing advantage of polymer heatsinks is quite vast, it enables more design freedom, it is lighter, lower thermal expansion, high breakdown voltages and less expensive to manufacture compared to aluminium heatsinks. Aluminium heatsinks are in certain applications machined from a solid aluminium billet with a CNC milling machine, but the polymer heatsinks require the manufacture of a once-off mould and thereafter heatsink cost turns out much lower, even for complex forms. Comparing aluminium to the polymer and epoxy thermal conductivity, it is about 3 times higher, but adding a heat conductive powder improved the thermal conductivity to less than 2 times compared to aluminium, making it viable for heatsink applications. Furthermore, careful design of the junction temperatures need to be performed, indicating that polymer heatsinks are, for the time being, more suited for lower power converters of less than $120 \mathrm{~W}$. It was noted that future commercial SiC MOSFET devices might tolerate a significant high 
reliable operating junction temperature, making these devices possible candidates for polymer heatsink applications in transportation power electronic devices where weight as well as cost is important, although care should be taken with too high junction temperatures due to thermal runaway for some SiC devices. It can also be considered in highly corrosive environments such as in sea water and it was shown to be well applied in robust outdoor applications.

\section{REFERENCES}

[1] Zhou, Y., Zhu, Y., Song, Q., Jin, Z., Yang, D., Yu, X.: "Prediction and reduction of electromagnetic conducted emission in active clamp forward converter", IEEE Electromagnetic Compatibility (EMC) Symposium, Long Beach, USA, 14-19 Aug. 2011, pp. 729-733.

[2] Britto, K. R. A., Vimala, R., Dhanasekaran, R., Saranya, B.: "Modelling of conducted EMI in flyback switching power converters", IEEE, Electronics and Control Engineering (ICONRAEeCE), Sivakasi, 15-17 Dec. 2011, pp. 377- 383.

[3] van Wyk, J.D., Lee, F.C.: "On a Future for Power Electronics“, IEEE Journal of Emerging and Selected Topics in Power Electronics, June 2013, 1, (2), pp. 59-72.

[4] Williams, T.: "Characterisation of emissions due to power electronics heatsinks," International Symposium on Electromagnetic Compatibility, Brugge, 2-6 Sept. 2013, pp. 616-621.

[5] Kulanayagam, J., Hagmann, J. H., Hoffmann, K. F., Dickmann, S.: "Reduction of heat sink common-mode currents in switching mode power supply circuits", Advances in Radio Science, Published by Copernicus Publications on behalf of the URSI Landesausschuss in der Bundesrepublik Deutschland e.V, 2011, 9, pp. 317-321.

[6] Trofimov, Y.V., Lishik, S.I., Pershukevich, P.P.: "On application of heat-conductive plastics in LED technology", Semiconductor Physics, Quantum Electronics \& Optoelectronics, 2013, 16, pp. 198-200. 
[7] Lee, G., Park, M., Kim, J., Lee, J. I., Yoon, H. K.: "Enhanced Thermal Conductivity of Polymer Composites Filled with Hybrid Filler", Composites Part A, Applied Science and Manufacturing, May 2006, 37, pp. 727-734.

[8] Yoon, Y. S., Oh, M. H., Kim, A. Y., Kim, N.: "The Development of Thermal Conductive Polymer Composites for Heat Sink", Environmental Materials and Component R\&D Center, Automotive Technology Institute, Cheonan, Chungnam, South Korea, June 2012, pp. 330-912.

[9] Lilli Manolis Sherman. (2001). Plastics That Conduct Heat [Online]. Available: http://www.ptonline.com/articles/plastics-that-conduct-heat

[10] Bahadur, R., Bar-Cohen, A.: "Thermal performance limits of polymer composite pin fin heat sinks", Electronic Components and Technology Conference, 31 May - 3 June 2005, 2, pp. 17201727.

[11] Ryu, S.H., Ryu, B. A., Hull, S., Dhar, L., Cheng, Zhang, Q.C., Richmond, J., Das, M.K., Agarwal, A., Palmour, J., Lelis, A.J.: "Performance, Reliability, and Robustness of 4H-SiC DMOSFETS", Materials Science Forum, April 2010, 645-648, pp. 969-974.

[12] Bennington-Castro, J.: (Dec. 2014). Polymer Blends with H-Bonds Increase Thermal Conductivity [Online]. Available: materials360online.com/newsDetails/50797

[13] Cevallos, J. G., Bergles, A. E., Cohen, A. P. R. B., Gupta, S. K.: "Polymer Heat ExchangersHistory, Opportunities, and Challenges", Heat Transfer Engineering, May 2012, 33, (13), pp. 10751093.

[14] Yoon, Y. S., Oh, M. H., Kim, A. Y., Kim, N.: "The Development of Thermal Conductive Polymer Composites for Heat Sink", Chem. Eng., 25 June 2012, 6, pp. 515-519. 
[15] Rondon-Pinilla, E., Morel, F., Vollaire, C., Schanen, J.L.: "Modeling of a Buck Converter With a SiC JFET to Prediect EMC Conducted Emissions," in IEEE Trans. on Power Electronics, May 2014, 29, (5), pp. 2246-2260.

[16] C. Buttay, R. Ouaida, H. Morel, D. Bergogne, C. Raynaud and F. Morel, "Thermal Stability of Silicon Carbide Power JFETs," in IEEE Trans. on Electron Devices, vol. 60, no. 12, pp. 41914198, Dec. 2013.

[17] C. Buttay, C. Raynaud, H. Morel, G. Civrac, M. L. Locatelli and F. Morel, "Thermal Stability of Silicon Carbide Power Diodes," in IEEE Trans. on Electron Devices, vol. 59, no. 3, pp. 761-769, March 2012.

[18] Pei, X., Zhang, K., Kang, Y., Chen, J.: “Analytical Estimation of Common-mode Conducted EMI in PWM Inverter", IEEE IAS, 2004, pp. 2651-2656.

[19] Vimala, R., Baskaran, K., Devarajan, N.: "Modelling and Filter Analysis of Differential-mode EMI for Switching Power Converters", European Journal of Scientific Research, April 2011, 52, (4), pp. 553-568.

[20] Jin, M., Weiming, M., Qijun, P., Jun, K., Lei, Z., Zhihua, Z.: "Identification of Essential Coupling Path Models for Conducted EMI Prediction in Switching Power Converters", in IEEE Trans. on Power Electronics, Nov 2006, 21, pp. 1795-1803.

[21] Mainali, K., Oruganti, R.: "Simple Analytical Models to Predict Conducted EMI Noise in a Power Electronic Converter", The 33rd Annual Conference of the IEEE Industrial Electronics Society (IECON), Taipei, Taiwan, 5-8 Nov. 2007.

[22] Grobler, I., Gitau, M. N.: "Low cost power lead extended pre-compliance conducted EMI measurement setup and diagnostics with compact LISN", IEEE ECCE Asia, Melbourne Australia, June 2013, pp. 1144-1149. 
[23] MIL-STD-461F, "Requirements for the Control of Electromagnetic Interference Characteristics of Subsystems and Equipment," Dept of Defense Interface Standard, December 2007.

[24] Russer, P.: "EMC measurements in the time-domain", IEEE General Assembly and Scientific Symposium, Istanbul, 13-20 Aug. 2011, pp. 1-35.

[25] Hireholi, S., Shashishekhar K.S. and Milton S. G., "Experimental Determination of Heat Transfer Coefficient by Natural Convection for a Commercially Available Heat Sink used for Cooling of Electronic Chips", International Journal of Mechanical and Industrial Engineering (IJMIE) ISSN, No. 2231-6477, Vol. 3, Iss. 1, pp. 43 - 45, 2013.

[26] Vishay Siliconix. (2015). Power MOSFETS [Online]. Available: http://www.vishay.com/docs/69993/an834.pdf 